\title{
Pancreatic Response to Hind Limb Suspension in Rats is Affected by Age
}

\author{
Kellie R. Nichols ${ }^{1}$, Parimal Chowdhury ${ }^{2, *}$ and Esther E. Dupont-Versteegden ${ }^{2,3}$
}

\author{
${ }^{I}$ University of Arkansas at Monticello, Monticello, Arkansas; ${ }^{2}$ Department of Physiology and Biophysics, University of \\ Arkansas for Medical Sciences, Little Rock, Arkansas and ${ }^{3}$ Division of Physical Therapy, Department of Rehabilitation \\ Sciences, University of Kentucky, Lexington, Kentucky, USA
}

\begin{abstract}
Disuse and aging are associated with changes in glucose metabolism and insulin responsiveness of skeletal muscle. However, their combined effects on the islets of Langerhans in the pancreas and serum insulin levels have not been studied. The goal of this study was to investigate the response of the pancreas to disuse, induced by hind limb suspension (HS), in young and old animals. Male Fisher 344 X Brown Norway rats at 6 (young) and 32 (old) months of age were subjected to 14 days HS. Serum insulin and pancreas morphology were examined. Serum insulin concentration was lower in old rats, and decreased significantly following HS in young, but not old rats. Islets of Langerhans in the pancreas showed a more diffuse appearance in the old rats independent of HS, but no statistically significant differences were observed in islet area, cells per islet, or area occupied by islets. However, in old animals, but not young, HS was associated with an increase in islet number. No differences were observed in the percentage or area of insulin positive cells in the pancreas. We conclude that the insulin secretion response to disuse is lost at old age, and this can not be explained by changes in islet size or insulin positive cell number. The implications of changed appearance and number of islets in old rats in response to HS remain to be investigated.
\end{abstract}

Key Words: Pancreas, hind limb suspension, islets of Langerhans, insulin, aging.

\section{INTRODUCTION}

Aging is associated with an increase in insulin resistance and a decrease in glucose tolerance in humans and animals [1-3], which predisposes older individuals for metabolic syndrome and associated diseases. One of the main contributors often associated with insulin resistance is physical inactivity $[3,4]$, such as occurs during bed rest and space flight [5]. The exact cause of the insulin resistance is currently under active investigation, and it has been shown that serum insulin levels decrease with aging as well as inactivity $[6,7]$, likely contributing to the enhanced glucose intolerance. The decreased serum insulin could be related to decreased insulin secretion by the $\beta$-cells of the pancreas as appears to occur with aging [3, 8]. In addition, inactivity induced by hind limb suspension (HS) or space flight is also associated with a decrease in serum insulin levels $[6,9,10]$, but the pancreatic responses have not currently been investigated. HS of rats has been used as a model for disuse, mimicking bed rest and space flight, and HS is initially associated with insulin resistance of glucose transport and metabolism in skeletal muscle [11-14]. More prolonged unweighting, i.e. longer than 3 days of HS, has been shown to enhance insulin action on carbohydrate metabolism in skeletal muscles $[6,12,13,15]$.

In the rat pancreas, $\beta$-cells expressing insulin, constitute $60-80 \%$ of all endocrine cells and are located in the central part of the islets [16]. Aging results in increases in pancreatic

\footnotetext{
*Address correspondence to this author at the College of Medicine, University of Arkansas for Medical Sciences, Department of Physiology and Biophysics, 4301 W Markham Street, Little Rock, AR 72205, USA; Tel: (501) 686-5443; Fax: (501) 686-8167; E-mail: PChowdhury@uams.edu
}

dry weight and the proportion of pancreas occupied by islet tissue, but general composition of the pancreas is unaffected $[17,18]$. Total pancreatic insulin decreases slightly and continually after maturity $[19,20]$. A decrease in the responsiveness of the $\beta$-cells to glucose stimulation is also affiliated with aging $[8,20,21]$. However, no study to date has evaluated the relative differences in islet composition occurring in response to aging combined with prolonged inactivity, such as occurs with HS.

Therefore, this study was designed to evaluate morphological changes in the endocrine tissues of the rat pancreas and to determine the response of insulin at 14 day HS in young and old rats. We hypothesized that changes in serum insulin levels would be accompanied by changes in the insulin-secreting cells of the pancreas and that the response of aged rats would be similar to young animals.

\section{METHODS}

\section{Animals and Experimental Procedures}

All procedures were performed in accordance with institutional guidelines for the care and use of laboratory animals and were approved by the Institutional Animal Care and use Committee at the University of Arkansas for Medical Sciences. Male Fischer 344 X Brown Norway rats (6 months and 32 months) were purchased from the National Institute on Aging. This strain of rat was chosen because it has increased longevity and decreased cumulative lesion incidence compared with other strains; therefore, aging aspects can be studied in the relative absence of disease [22]. The different age groups were chosen to reflect a mature rat (6 months) 
and an old rat at about $50 \%$ mortality (32 months). Rats of both age groups were divided into 2 groups ( $n=5$ per group): non-suspended control and hind limb suspended for 14 days. Rats were allowed free access to food and water. Animals were housed in a 12:12 hr light:dark cycle. Hind limb suspension was performed as previously described [23, 24]. Briefly, rats were anesthetized with pentobarbital sodium and a tail device containing a hook was attached with gauze and cyanoacrylate glue. Upon returning to consciousness, the tail device was connected via a thin cable to a pulley sliding on a vertically adjustable stainless steel bar running longitudinally above a high-sided cage with standard floor dimensions. During suspension, the rats cannot rest their hind limbs against any surface of the cage. After 14 days, the animals were anesthetized with pentobarbital sodium $(50 \mathrm{mg} / \mathrm{kg}$ body weight) and blood was obtained through heart puncture. Serum was prepared immediately and frozen at $-80^{\circ} \mathrm{C}$ until further use. Rats were euthanized with an overdose of pentobarbital sodium and the pancreases dissected, fixed in $10 \%$ buffered formalin, and embedded in paraffin wax for sectioning.

\section{Serum Insulin Analysis}

Serum insulin concentration was determined spectrophotometrically using a 1-2-3 Rat Insulin ELISA kit (American Laboratory Products Company, ALPCO, Windham, NH) according to the manufacturer's recommendations. Briefly, $25 \mu \mathrm{l}$ serum was assayed and compared to a standard curve with known values. Samples were incubated for 2 hours at room temperature in conjugation solution followed by incubation in substrate solution for 15 minutes. Optical density was read at $450 \mathrm{~nm}$ and serum insulin was calculated and expressed in $\mathrm{ng} / \mathrm{ml}$.

\section{Histology and Immunohistochemistry}

Pancreas sections (4-5 $\mu \mathrm{m})$ were cut on a microtome and stained with hematoxylin and eosin (H\&E) using standard procedures [25]. Sections were viewed and subsequently photographed using a Nikon microscope and imaging software (MetaView, Universal Imaging, Westchester, PA). Images of 10 random fields were then processed and analyzed using an image analysis program (Image J, National Institutes of Health, USA). Under blinded conditions, islets were manually traced and islet size and number were determined and normalized to area of pancreatic tissue. In addition, cell number per islet was counted.

Immunohistochemical determination of the presence of insulin was determined as follows. After deparaffinization, sections were fixed in methanol for 20 minutes at $4{ }^{\circ} \mathrm{C}$. Polyclonal rabbit anti-insulin (H-86) antibody (Santa Cruz Biotechnology, Santa Cruz, CA) was applied in a concentration of $8 \mu \mathrm{g} / \mathrm{ml}$ for 2 hours at room temperature, followed by incubation with a biotin-conjugated rat anti-rabbit $\mathrm{IgG}$ (Zymed, San Francisco, CA) at a 1:250 dilution in PBS for 1 hour at room temperature. Streptavidin-alkaline phosphatase was then added for 10 minutes at room temperature, followed by alkaline-phosphate substrate (Vector, Burlingame, CA) for color development (blue) as directed by manufacturer. Slides were dipped in Nuclear Fast Red (Sigma, St Louis, MO) solution for visualization of nuclei, dehydrated, and coverslipped. Sections were viewed and subsequently photographed monochromatically, and analyzed using a Nikon microscope and imaging software (Meta View, Universal Imaging, West Chester, PA) similar to methods as described [26]. For each animal 10 random areas from the pancreas were analyzed. Individual islets were manually traced and insulin positive area was calculated using a 12-bit scaling image of 0-4095 and a threshold range of 1000-3400. The percent insulin positive tissue area within the islets was calculated and the number of insulin positive cells per islet was counted.

\section{Statistical Analysis}

Two way analysis of variance was used to determine statistically significant differences between the age and experimental groups. In case of significant differences, Tukey posthoc test was used. Statistical significance was assumed at $\mathrm{P}$ $<0.05$.

\section{RESULTS}

\section{Serum Insulin Concentration}

Serum insulin concentrations were measured to determine the effect of aging and hind limb suspension. Aging was associated with a significant decrease in serum insulin concentration (Fig. 1). Additionally, serum insulin was significantly decreased in response to hind limb suspension in young but not in old rats (Fig. 1), indicating that the response to disuse affecting serum insulin concentration is abolished with age.

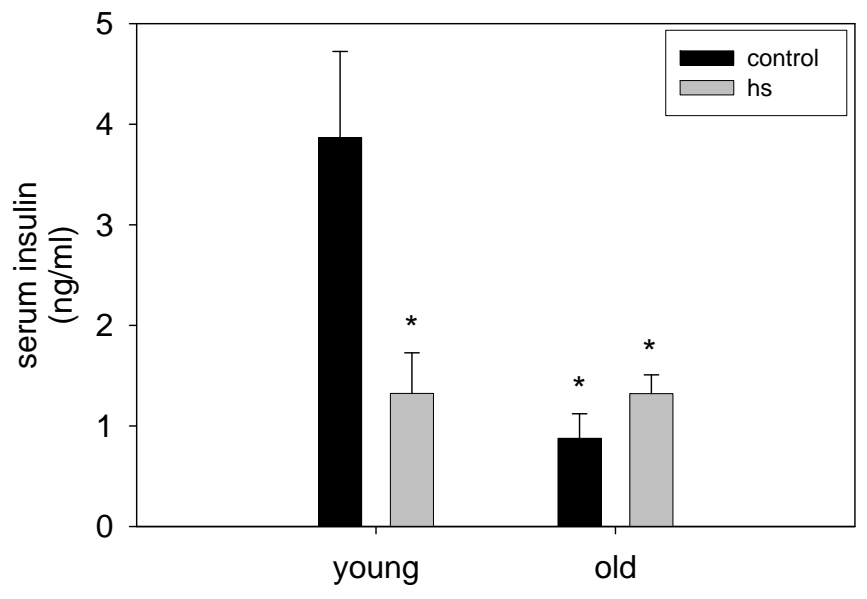

Fig. (1). Serum insulin concentration decreases with aging and hind limb suspension. Serum insulin concentration measured in $\mathrm{ng} / \mathrm{ml}$ in young (6 months) and old (32 months) rats $(\mathrm{n}=5)$ under control conditions (control, black bars) or after 14 days of hind limb suspension (hs, gray bars). Values are means \pm SE. * indicates significant difference from young control, $\mathrm{p}<0.05$.

\section{Histology of the Islets of Langerhans}

To investigate whether differences in pancreatic islets could account for the changes in serum insulin, histological and immunohistochemical analysis of the pancreases of the rats was performed. Gross examination of H\&E slides showed that islets of young rats appeared rounded and predominately equal in size (Fig. $\mathbf{2 A}$ and $\mathbf{B}$ ). The contours of the islets of old rats are more often irregular or oval shaped 

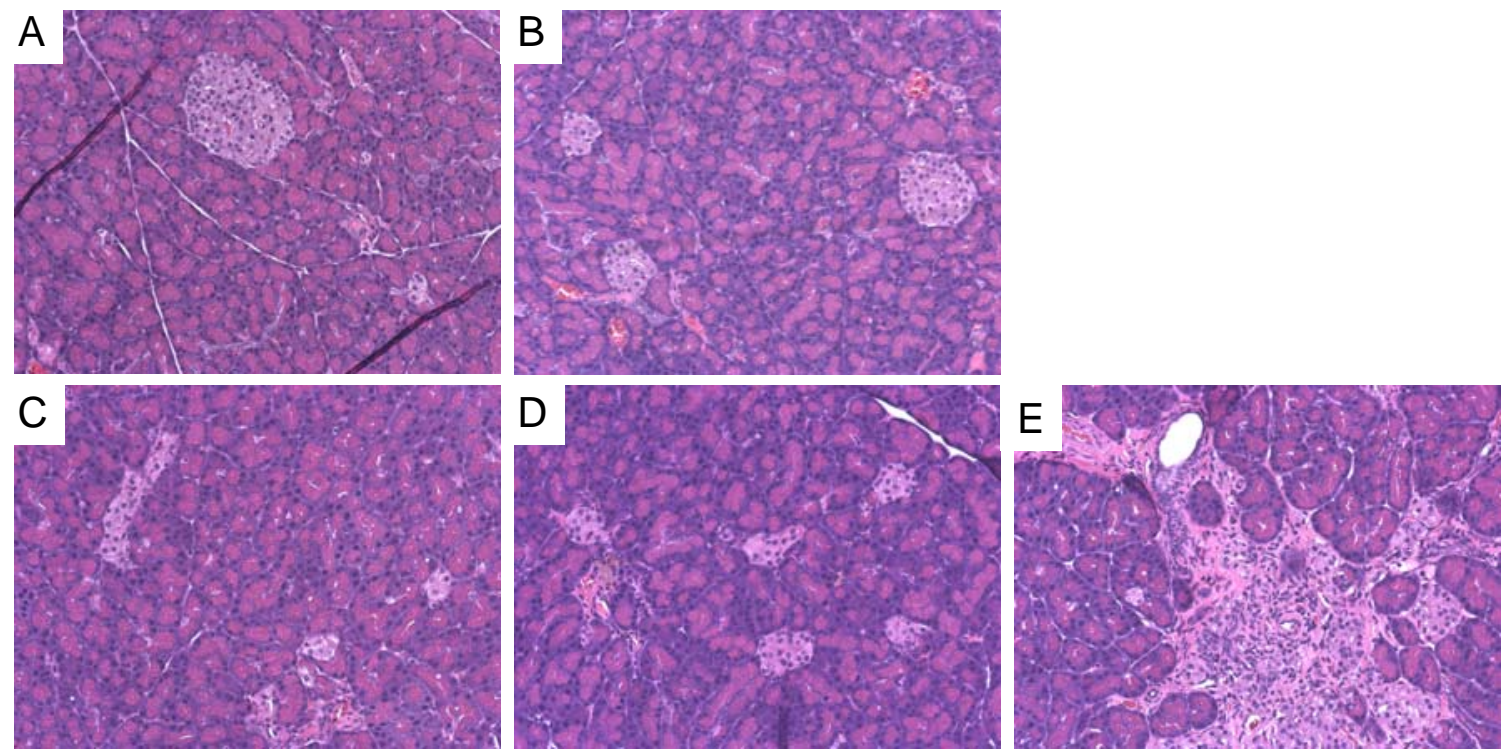

Fig. (2). Morphology of pancreatic islets determined by cross sections. Representative cross sections of areas of the pancreas with islets from young (6 months, $\mathbf{A}$ and $\mathbf{B}$ ) and old (32 months, $\mathbf{C}$ and $\mathbf{D})$ rats under control conditions ( $\mathbf{A}$ and $\mathbf{C}$ ) or after 14 days of hind limb suspension (B and D). Quantification of islet morphology is summarized in Table $\mathbf{1}$ and Fig. (3). Very large islets with irregular size were occasionally observed in old rats in particular after hind limb suspension (example in E). Magnification 40X.

and there seemed to be greater variability in size between islets (Fig. 2C and D). Hind limb suspension did not overtly change the appearance of islets in young rats. However, in old rats subjected to hind limb suspension very large islets were occasionally observed (example Fig. 2E). These islets were never observed in pancreas from young rats and only rarely in old control animals.

To quantify the morphological changes with aging and hind limb suspension, the number of islets, the islet area, the number of cells per islet, and the islet area per total pancreas area were determined (Table $\mathbf{1}$ and Fig. 3). From qualitative observations it appeared that the islets in old rats were larger and therefore we measured both the area of islets per cross sectional area of pancreas and the number of islets. Results indicated that aging was associated with an increase in number of islets normalized to measured pancreas area (Fig. 3). However, hind limb suspension did not change the number of islets in either young or old rats (Fig. 3).

Additional morphological analysis was conducted by measuring average islet area, number of cells per islet, and islet area normalized to total area with either aging or hind limb suspension (Table 1). No significant effects were observed associated with either aging or hind limb suspension in average islet area, number of cells per islet, or islet area

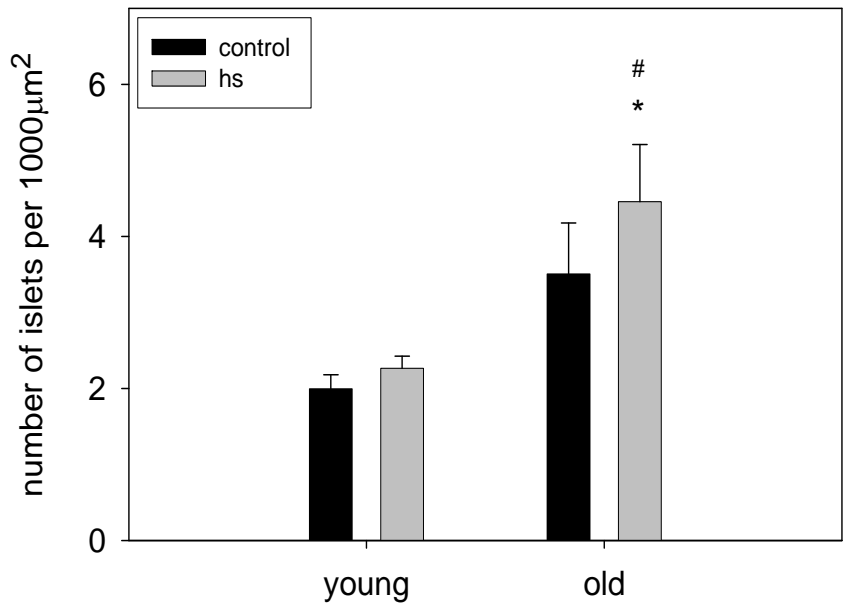

Fig. (3). Number of islets is increased with age and hind limb suspension in the old. Islet number normalized to pancreatic area counted in young (6 months) and old (32 months) rats $(n=5)$ under control conditions (control, black bars) or after 14 days of hind limb suspension (hs, gray bars). Values are means \pm SE. $*$ indicates significant difference from young control, \# indicates significant difference from young hs $\mathrm{p}<0.05$. Main age effect: $\mathrm{p}=0.002$.

Table 1. Morphological Analysis of Pancreatic Islets

\begin{tabular}{|c|c|c|c|c|}
\hline \multirow{2}{*}{} & \multicolumn{2}{|c|}{ Young } & \multicolumn{2}{c|}{ Old } \\
\cline { 2 - 5 } & Control & HS & Control & HS \\
\hline \hline Average islet area $\left(\mathrm{mm}^{2}\right)$ & $7750 \pm 1877$ & $9416 \pm 2641$ & $5477 \pm 545$ & $7764 \pm 1622$ \\
\hline Number of cells per islet & $60.0 \pm 8.3$ & $51.1 \pm 15.3$ & $37.8 \pm 3.6$ & $2.02 \pm 0.56$ \\
\hline Islet area per total area $(\%)$ & $1.61 \pm 0.43$ & $1.99 \pm 0.43$ & $3.07 \pm 0.42$ \\
\hline
\end{tabular}

Values are means $\pm \mathrm{SE}$. 
normalized to total area (Table 1). There was a trend for islet area to be increased with hind limb suspension in the old rats, but this failed to reach significance.

In order to investigate whether the changes in serum insulin levels were due to a decreasing number of insulin producing cells in the islets, pancreas sections were immunostained with insulin antibody (Fig. 4). Insulin positive staining was observed in the central portion of the islets and no obvious visual differences in staining were observed in the different groups (Fig. 4). Quantification of insulinpositive staining indicated no changes with either age or hind limb suspension in the area or cell number within the islets that were positive for insulin (Table 2 ).

\section{DISCUSSION}

In this study the response of pancreatic tissue of young and old rats to disuse induced by HS was investigated. We showed that HS induced a decrease in serum insulin concentration in young, but not old rats, in which insulin was already lower than in young under control conditions. Therefore, the insulin response to HS has been lost at old age, since old rats did not exhibit the same decrease in serum insulin after disuse as the young animals. The decrease in serum insulin both with age, and HS in young rats was not associated with a decrease in pancreatic islets or a change in insulin secreting cell number. In contrast, it occurred in the face of an increase in the number of islets in aged rats, particularly with HS. Even though the visual appearance of the pancreases from old HS rats was changed, not all of the islets of the old animals appeared enlarged and abnormal, and the quantitative data confirmed this finding. Because size, total area, and number of cells of islets, and cell number and area of insulin secreting cells was not changed even though insulin levels were lower, we suggest that the function of the insulin secreting cells is decreased with age. Indeed, aging
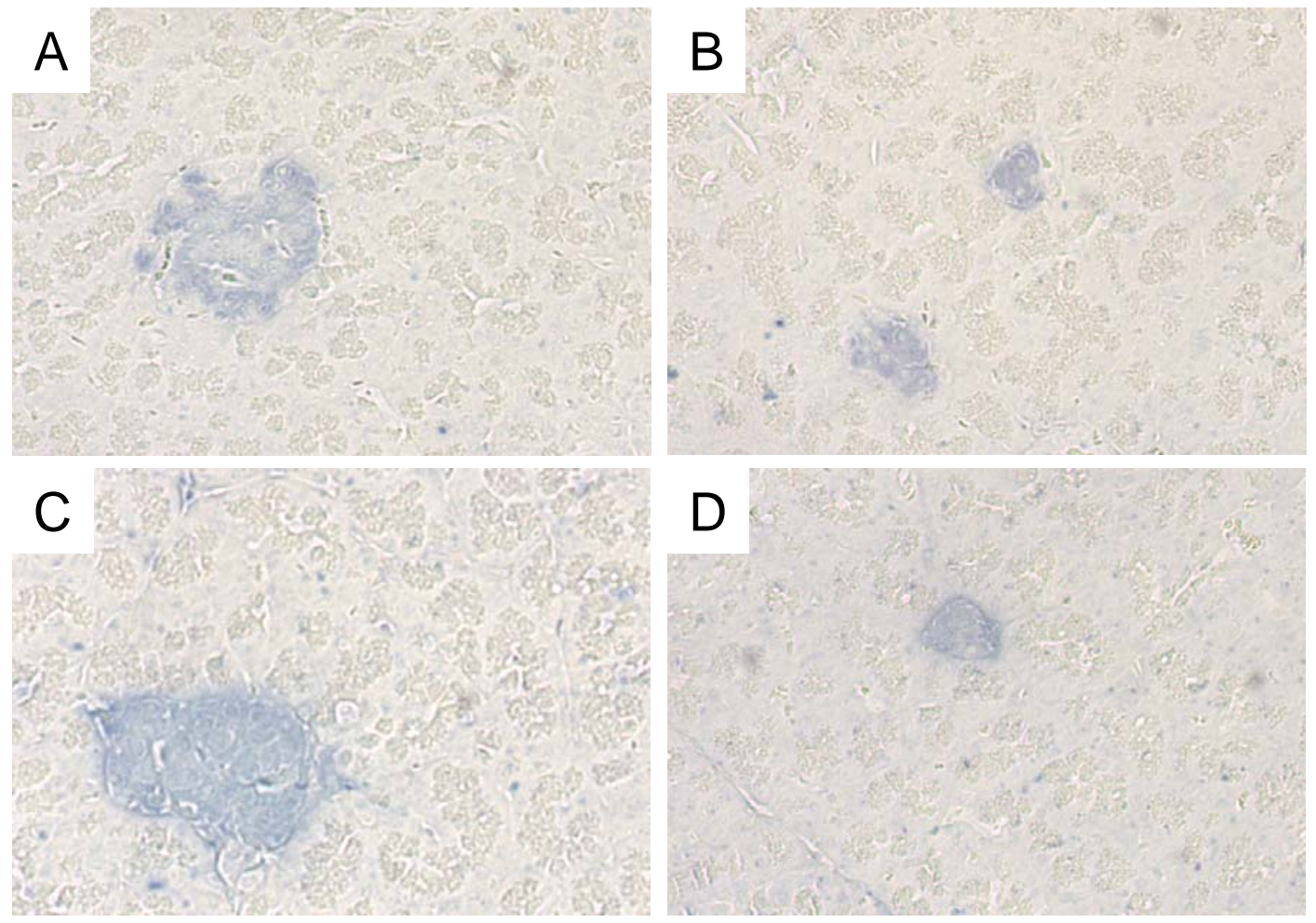

Fig. (4). Cross sections of pancreas immunoreacted with insulin antibody. Representative cross sections of areas with islets in the pancreas immunoreacted with insulin antibody (blue) from young (6 months, $\mathbf{A}$ and $\mathbf{B}$ ) and old (32 months, $\mathbf{C}$ and $\mathbf{D})$ rats under control conditions (A and $\mathbf{C}$ ) or after 14 days of hind limb suspension (B and $\mathbf{D})$. Quantification of insulin immunoreactivity is summarized in Table $\mathbf{2}$. Magnification 40X.

Table 2. Quantitation of Immunoreactivity to Insulin in Pancreatic Islets

\begin{tabular}{|c|c|c|c|c|}
\hline \multirow{2}{*}{} & \multicolumn{2}{|c|}{ Young } & \multicolumn{2}{c|}{ Old } \\
\cline { 2 - 5 } & Control & HS & Control & HS \\
\hline \hline Insulin positive area (\%) & $30.8 \pm 5.7$ & $27.7 \pm 4.0$ & $29.4 \pm 6.6$ & $26.4 \pm 4.7$ \\
\hline Insulin positive cells (\%) & $74.5 \pm 8.3$ & $77.5 \pm 14.2$ & $63.1 \pm 10.5$ & $56.5 \pm 9.4$ \\
\hline
\end{tabular}


has been associated with a decrease in responsiveness of the beta cells to glucose stimulation as well as decreased relative insulin secretion by the beta cells [8,19-21]. We suggest that the increase in number of islets in the aged HS rats is a failed compensatory response. In addition, increases in islet volume due to an increase in beta cell number with age correlates with a decrease in the insulin secretory response [17, $18]$.

By contrast, we did not observe any changes in the pancreatic parameters in response to HS in young rats, indicating that the decrease in serum insulin with HS could be due to a decrease in insulin secreting function of the beta cells or to an increased usage of insulin in peripheral tissues. Bonen et al. [6] showed that rats hindlimb suspended for 28 days exhibited marked increments in insulin binding and glucose metabolism in the soleus muscle suggesting increased utilization of insulin with subsequent decrease in circulating serum levels. Similar responses were noted in 6-day unloaded rat soleus muscle [15] and additional studies showed that HS caused a decrease in insulin receptors in skeletal muscle [27] and activation of insulin-independent pathways mediating glucose uptake [28]. The changes in the insulin levels could be associated with plasma insulin oscillations noted as metabolic defects in Type-2 diabetes [29, 30] or oscilllations of metabolism in the pancreas [31]. However, the decreased function of beta cells in response to HS in young animals in particular could also be due to an increase in oxidative stress. We and others have shown that HS induced oxidative stress in brain and hind limb muscles of rats [32-35], and more recently we found a global increase in oxidative damage in all organs including pancreas in rats following 14 days of HS [36]. It is possible that oxidative damage in aged rats is already elevated to such an extent that insulin secretion is at a minimal level and HS does not alter this any further.

In summary, HS and aging is not associated with extensive changes in the morphology of pancreatic islets, even though insulin levels are decreased with both age and HS in young rats. We propose that the insulin secretory function of the individual cells may be changed possibly due to oxidative damage in response to age and HS, and future studies should be directed towards investigating this possibility.

\section{ACKNOWLEDGMENTS}

The authors wish to thank Beau Strotman, Cathy Gurley, and Oxana Lazarenko for their technical assistance. $\mathrm{KN}$ was supported by a Summer Research Fellowship through the NIH Grant \# P20 RR-16460 from the IDeA Networks of Biomedical Research Excellence (INBRE) Program of the National Center for Research Resources. This work was supported by the following NIH grants AG20407 and AR47577.

\section{REFERENCES}

[1] Iossa, S.; Mollica, M.P.; Lionetti, L.; Crescenzo, R.; Tasso, R.; Liverini, G. A possible link between skeletal muscle mitochondrial efficiency and age-induced insulin resistance. Diabetes, 2004, 53, 2861-2866.

[2] Chang, A.M.; Halter, J.B. Aging and insulin secretion. Am. J. Physiol. Endocrinol. Metab., 2003, 284, E7-12.

[3] Scheen, A.J. Diabetes mellitus in the elderly: insulin resistance and/or impaired insulin secretion? Diabetes Metab., 2005, 31(Spec No 2), 5S27-25S34.
[4] LaMonte, M.J.; Blair, S.N.; Church, T.S. Physical activity and diabetes prevention. J. Appl. Physiol., 2005, 99, 1205-1213.

[5] Strollo, F. Hormonal changes in humans during spaceflight. $A d v$ Space. Biol. Med., 1999, 7, 99-129.

[6] Bonen, A.; Elder, G.C.; Tan, M.H. Hindlimb suspension increases insulin binding and glucose metabolism. J. Appl. Physiol., 1988, 65, 1833-1839.

[7] Masoro, E.J.; McCarter, R.J.; Katz, M.S.; McMahan, C.A. Dietary restriction alters characteristics of glucose fuel use. J. Gerontol., 1992, 47, B202-208.

[8] Perfetti, R.; Rafizadeh, C.M.; Liotta, A.S.; Egan, J.M. Agedependent reduction in insulin secretion and insulin mRNA in isolated islets from rats. Am. J. Physiol., 1995, 269, E983-990.

[9] Macho, L.; Fickova, M.; Zorad, S.; Kvetnansky, R. Changes of insulin binding in rat tissues after exposure to stress. Physiol. Res., 1999, 48, 51-58.

[10] Tobin, B.W.; Uchakin, P.N.; Leeper-Woodford, S.K. Insulin secretion and sensitivity in space flight: diabetogenic effects. Nutrition, 2002, $18,842-848$.

[11] Henriksen, E.J.; Tischler, M.E. Glucose uptake in rat soleus: effect of acute unloading and subsequent reloading. J. Appl. Physiol., 1988, 64, 1428-1432.

[12] O'Keefe, M.P.; Perez, F.R.; Sloniger, J.A.; Tischler, M.E.; Henriksen, E.J. Enhanced insulin action on glucose transport and insulin signaling in 7-day unweighted rat soleus muscle. J. Appl. Physiol., 2004, 97, 63-71.

[13] Hirose, M.; Kaneki, M.; Sugita, H.; Yasuhara, S.; Martyn, J.A. Immobilization depresses insulin signaling in skeletal muscle. Am. J. Physiol. Endocrinol. Metab., 2000, 279, E1235-1241.

[14] Flier, S.N.; Kulkarni, R.N.; Kahn, C.R. Evidence for a circulating islet cell growth factor in insulin-resistant states. Proc. Natl. Acad. Sci. USA, 2001, 98, 7475-7480.

[15] Henriksen, E.J.; Tischler, M.E.; Johnson, D.G. Increased response to insulin of glucose metabolism in the 6-day unloaded rat soleus muscle. J. Biol. Chem., 1986, 261, 10707-10712.

[16] Wieczorek, G.; Pospischil, A.; Perentes, E. A comparative immunohistochemical study of pancreatic islets in laboratory animals (rats, dogs, minipigs, nonhuman primates). Exp. Toxicol. Pathol., 1998, 50, 151-172.

[17] Reaven, E.P.; Gold, G.; Reaven, G.M. Effect of age on glucosestimulated insulin release by the beta-cell of the rat. J. Clin. Invest., 1979, 64, 591-599.

[18] Reaven, E.P.; Reaven, G.M. Structure function changes in the endocrine pancreas of aging rats with reference to the modulating effects of exercise and caloric restriction. J. Clin. Invest., 1981, 68 , 75-84.

[19] Jia, D.M.; Fukumitsu, K.I.; Tabaru, A.; Akiyama, T.; Otsuki, M. Troglitazone stimulates pancreatic growth in congenitally CCK-A receptor-deficient OLETF rats. Am. J. Physiol. Regul. Integr. Comp. Physiol., 2001, 280, R1332-1340.

[20] Lamberts, S.W.; van den Beld, A.W.; van der Lely, A.J. The endocrinology of aging. Science, 1997, 278, 419-424.

[21] Utsugi, T.; Ohno, T.; Ohyama, Y.; Uchiyama, T.; Saito, Y.; Matsumura, Y.; Aizawa, H.; Itoh, H.; Kurabayashi, M.; Kawazu, S.; Tomono, S.; Oka, Y.; Suga, T.; Kuro-o, M.; Nabeshima, Y.; Nagai, R. Decreased insulin production and increased insulin sensitivity in the klotho mutant mouse, a novel animal model for human aging. Metabolism, 2000, 49, 1118-1123.

[22] Lipman, R.; Chrisp, E.; Hazzard, D.; Bronson, R. Pathologic characterization of Brown Norway, Brown Norway X Fischer 344, and Fischer 344 X Brown Norway rats with relation to age. J. Gerontol. Biol. Sci., 1996, 51A, B54-B59.

[23] Gallegly, J.C.; Turesky, N.A.; Strotman, B.A.; Gurley, C.M.; Peterson, C.A.; Dupont-Versteegden, E.E. Satellite cell regulation of muscle mass is altered at old age. J. Appl. Physiol., 2004, 97, 10821090.

[24] Leeuwenburgh, C.; Gurley, C.M.; Strotman, B.A.; DupontVersteegden, E.E. Age-related differences in apoptosis with disuse atrophy in soleus muscle. Am. J. Physiol. Regul. Integr. Comp. Physiol., 2005, 288, R1288-1296.

[25] Boenisch, T.F.A.; Stead, R.H. Handbook immunochemical staining methods. Carpinteria, CA: DAKO Corporation, 1989.

[26] Liu, J.L.; Coschigano, K.T.; Robertson, K.; Lipsett, M.; Guo, Y.; Kopchick, J.J.; Kumar, U.; Liu, Y.L. Disruption of growth hormone receptor gene causes diminished pancreatic islet size and in- 
creased insulin sensitivity in mice. Am. J. Physiol. Endocrinol. Metab., 2004, 287, E405-413.

[27] Stuart, C.A.; Kidder, L.S.; Pietrzyk, R.A.; Klein, G.L.; Simmons, D.J. Rat tail suspension causes a decline in insulin receptors. Exp. Toxicol. Pathol., 1993, 45, 291-295.

[28] Hilder, T.L.; Baer, L.A.; Fuller, P.M.; Fuller, C.A.; Grindeland, R.E.; Wade, C.E.; Graves, L.M. Insulin-independent pathways mediating glucose uptake in hindlimb-suspended skeletal muscle. $J$. Appl. Physiol., 2005, 99, 2181-2188.

[29] Matveyenko, A.V.; Butler, P.C. Beta-cell deficit due to increased apoptosis in the human islet amyloid polypeptide transgenic (HIP) rat recapitulates the metabolic defects present in type 2 diabetes. Diabetes, 2006, 55, 2106-2114.

[30] Mao, C.S.; Berman, N.; Ipp, E. Loss of entrainment of highfrequency plasma insulin oscillations in type 2 diabetes is likely a glucose-specific beta-cell defect. Am. J. Physiol. Endocrinol. Metab., 2004, 287, E50-54

[31] Bergsten, P.; Westerlund, J.; Liss, P.; Carlsson, P.O. Primary in vivo oscillations of metabolism in the pancreas. Diabetes, 2002, 51, 699-703.
[32] Lawler, J.M.; Song, W.; Demaree, S.R. Hindlimb unloading increases oxidative stress and disrupts antioxidant capacity in skeletal muscle. Free Radic. Biol. Med., 2003, 35, 9-16.

[33] Chowdhury, P.; Soulsby, M. Lipid peroxidation in rat brain is increased by simulated weightlessness and decreased by a soyprotein diet. Ann. Clin. Lab. Sci., 2002, 32, 188-192.

[34] Hofer, T.; Marzetti, E.; Xu, J.; Seo, A.Y.; Gulec, S.; Knutson, M.D.; Leeuwenburgh, C.; Dupont-Versteegden, E.E. Increased iron content and RNA oxidative damage in skeletal muscle with aging and disuse atrophy. Exp. Gerontol., 2008, in press.

[35] Arbogast, S.; Smith, J.; Matuszczak, Y.; Hardin, B.J.; Moylan, J.S.; Smith, J.D.; Ware, J.; Kennedy, A.R.; Reid, M.B. Bowman-Birk inhibitor concentrate prevents atrophy, weakness, and oxidative stress in soleus muscle of hindlimb-unloaded mice. J. Appl. Physiol., 2007, 102, 956-964.

[36] Chowdhury, P.; Soulsby, M.; Kim, K. L-carnitine influence on oxidative stress induced by hind limb unloading in adult rats. Aviat. Space. Environ. Med., 2007, 78, 554-556.

(C) Nichols et al.; Licensee Bentham Open.

This is an open access article licensed under the terms of the Creative Commons Attribution Non-Commercial License (http://creativecommons.org/licenses/ by-nc/3.0/) which permits unrestricted, non-commercial use, distribution and reproduction in any medium, provided the work is properly cited. 